\title{
A sustentabilidade e a continuidade de redes de articulação: o caso do lluminar Campinas
}

\section{The sustainability and continuity of joint networks: the case of Iluminar Campinas}

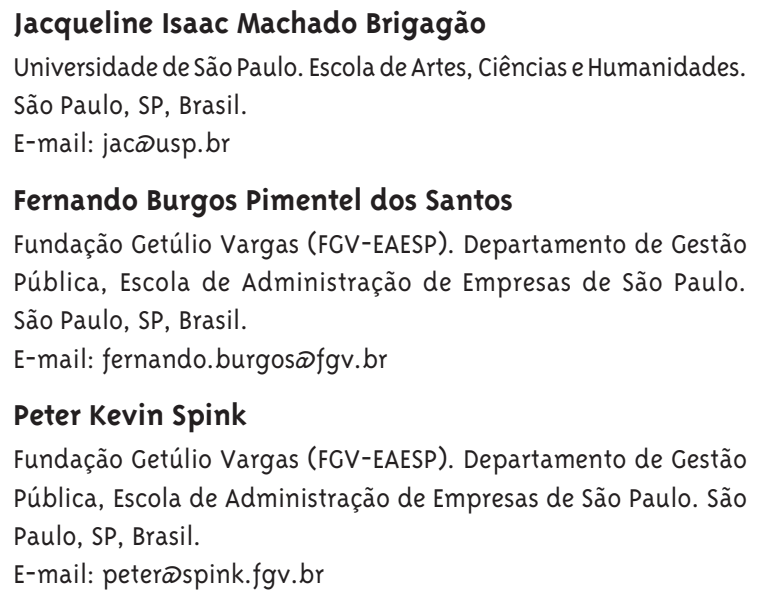

\section{Correspondência}

Jacqueline Isaac Machado Brigagão

Rua Arlindo Betio, 1000. Ermelino Matarazzo. São Paulo, SP, Brasil. CEP 03828-000.

\section{Resumo}

Este trabalho analisa a trajetória de uma política pública municipal de saúde que organizou e sustentou uma rede complexa e intersetorial de cuidados a pessoas em situação de violência sexual no município de Campinas - SP. A partir da perspectiva de que, para cuidar das pessoas que sofreram violência sexual, faz-se necessário utilizar os diversos serviços públicos existentes, a rede foi articulada envolvendo vários segmentos, como saúde, segurança pública, educação, assistência social, sociedade civil organizada e universidades. 0 texto apresenta e discute os diferentes momentos desse processo durante o período de 2001 a 2014, desde a inclusão do tema de cuidado às pessoas que sofreram violência na agenda governamental local até as ações de disseminação da política para outros municípios. Busca-se analisar as estratégias-chave que garantiram a conectividade da rede e a sustentabilidade ao longo do tempo, bem como demonstrar a potencialidade do local na elaboração e desenvolvimento de politicas de saúde.

Palavras-chave: Políticas Públicas; Saúde; Violência Sexual. 


\section{Abstract}

This paper discusses the trajectory of a municipal public health policy that organized and sustained a complex and intersectorial network of support for victims of sexual violence in the city of Campinas. From the perspective that using the existing public services is appropriate to take care of victims of sexual violence, the network was articulated involving various segments, such as health, public safety, education, social welfare, civil society organizations and universities. This paper presents and discusses some of the key moments of the program during 2001-2014, from the inclusion of the issue on the local government agenda to the transference to other municipalities. We aim to analyze the key strategies that ensured network connectivity and sustainability over time and to demonstrate the local capability in the design and development of health policies.

Keywords: Public Policy; Health; Sexual Violence.

\section{Introdução}

A sustentabilidade e a continuidade das ações na esfera pública é uma questão paradoxal. Institucionalmente, democracias são construídas a partir da noção da disputa entre plataformas e propostas de ação, cujos valores são distintos e emergem do pressuposto de que, ao perder a disputa, os perdedores aceitariam os resultados e voltariam a disputar. Explícita, aqui, é a possibilidade de mudança, autorizada pelo pleito, e a descontinuidade potencial das ações. Ao mesmo tempo, há uma ideia igualmente clara de um universo de assuntos, alguns dos quais são considerados - de maneira deliberativa - importantes de serem mantidos, independentemente de quem foi eleito. Gutmann e Thompson (2004) observam que, embora haja limites às possibilidades de deliberação, ela existe explícita ou implicitamente. Continuidade e descontinuidade não são, a priori, situações positivas ou negativas.

No Brasil, a partir da Constituição de 1988 e especialmente - mas não exclusivamente -no contexto social, tem havido muitas discussões sobre a importância da continuidade de arranjos interorganizacionais. Talvez um dos mais centrais - tanto por sua importância no dia a dia quanto por sua influência - tem sido o conjunto de propostas articuladas em torno do Sistema Único de Saúde (SUS), especialmente em relação à atuação "articulada” em rede. Por serem propostas organizativas e não focadas nesse ou naquele eixo de atendimento, podem ser consideradas - na linguagem de políticas públicas - como metas políticas, no sentido de orientar a maneira pela qual muitas atividades diferentes e específicas são desenvolvidas. Portanto, segue a pergunta: quais são os fatores-chave - além de leis, portarias e os demais elementos de nosso mundo institucional - de sustentação dessas "meta-abordagens"? Como criar a base de uma articulação com continuidade na prática?

O Programa Gestão Pública e Cidadania do Centro de Estudos de Administração e Governo (CEAPG) da Fundação Getúlio Vargas, em São Paulo, trabalhou dez anos na identificação e disseminação de experiências inovadoras de governos subnacionais que não somente melhoraram os serviços públicos, 
mas contribuíram para a construção da cidadania (Spink e Farah, 2008). A base de dados assim construída permitiu a análise de uma série de questões sobre a continuidade da inovação nos governos locais em que a dimensão intersetorial teve um papel importante tanto em relação aos diferentes setores de governo quanto às dimensões governo e sociedade civil. 0 programa Iluminar Campinas foi uma dessas experiências.

Nosso primeiro contato com o programa ocorreu em 2004, e desde então temos acompanhado a sua trajetória por meio de visitas, conversas e leitura de documentos. A descrição analítica que segue é resultado dessas visitas, análises de documentos e discussões com a gestora do programa, que concordou com a sua identificação no texto. A experiência do Iluminar dialoga com um conjunto de ideias sobre as ações de interesse público, a construção de agendas e a sustentabilidade de articulações. Por mais de uma década, e apesar das mudanças de partido na gestão municipal e dos desafios do cotidiano da administração pública, o programa vem crescendo em importância local, regional e nacional.

\section{Os percursos iniciais}

O Iluminar Campinas é uma ação pública de âmbito municipal que organiza uma rede intersetorial e interinstitucional de serviços de saúde, educação, assistência social, jurídica e de cidadania para cuidar das pessoas que sofreram violência sexual.

Vale destacar que, no cenário nacional, as feministas, ativistas de movimentos sociais de luta por direitos humanos e saúde, os movimentos de mulheres, entre outros, desde as décadas de 1960 e 1970, têm denunciado os diversos tipos de violência presentes na sociedade brasileira e pressionando o governo para realizar ações e políticas de enfrentamento da violência (Blay, 2003).

No contexto da violência sexual, apesar do Código Penal Brasileiro de 1940 permitir o aborto nos casos em que a gravidez seja resultante de estupro, havia poucos serviços de saúde que de fato realizavam o aborto legal até 1998, quando o Ministério da Saúde estabeleceu a norma técnica "Prevenção e tratamento dos agravos à saúde resultantes da violência sexual contra mulheres e adolescentes”. Isso possibilitou a multiplicação, por todo o país, dos serviços de saúde destinados ao atendimento dos casos de aborto previstos na legislação nacional (Soares, 2003).

No ano de 2005, o Ministério da Saúde publicou uma revisão da portaria e retirou a obrigatoriedade de apresentação de boletim de ocorrência para a realização dos abortos previstos em lei. Assim, o Ministério assume que as pessoas que sofreram violência sexual necessitam de cuidados específicos em saúde, independente das questões jurídicas/ policiais (Pedrosa, 2010).

Um outro aspecto apontado por profissionais de saúde como fundamental para efetuar o cuidado às pessoas que sofreram violência sexual foi o fato do Ministério da Saúde ter publicado o protocolo de atendimento específico para essa população. 0 protocolo padroniza e explicita os procedimentos a serem realizados, como os exames e medicações, bem como facilita a organização do fluxo dentro de serviço de saúde (Pedrosa; Spink, 2011).

O tema violência sexual apareceu explicitamente na agenda governamental municipal de Campinas em 200o, ano da realização do Seminário de Atendimento às Vítimas de Violência Sexual de Campinas, do qual participaram gestores e profissionais das áreas da saúde, educação e segurança pública das esferas estadual e municipal. Verônica Alencar (que viria a ser a coordenadora do programa Iluminar) estava presente e participou ativamente das discussões sobre as implicações da violência sexual na saúde da população. Entre os resultados do seminário, é importante destacar o mapeamento da rede de serviços existentes e a "Carta de Campinas" na qual os participantes solicitavam providências do poder público em relação ao atendimento às pessoas que sofreram violência sexual. Fica evidente que Verônica Alencar, médica da Secretária Municipal de Saúde de Campinas à época, já tinha um papel ativo na defesa dos direitos dessas vítimas, podendo ser considerada - na linguagem analítica de Kingdon (1997) - uma empreendedora da temática (policy entrepreneur), na medida em que ajudou a articular essa questão como um problema relevante a ser endereçado pelo poder público municipal. Entretanto, 
como Kingdon aponta em sua análise, problemas também precisam de possibilidades de solução, já que competem com outras questões em circulação e precisam de financiamento. Todos esses fatores, mais a dinâmica de eventos político-sociais, podem abrir ou fechar janelas de oportunidade.

Naquele momento, a janela foi um edital do Ministério da Saúde, no âmbito do Programa de DST/ Aids, que financiava ações nos munícipios. O projeto do Progama Iluminar foi enviado para o edital e foi contemplado com 100 mil reais para o desenvolvimento das ações iniciais. Com isso, o programa não somente entrou para a agenda governamental do município de Campinas, como recebeu recursos que permitiam a sua realização. Mas, naquele momento, era apenas um programa, ainda não havia sido institucionalizado de modo a tornar-se uma política pública consolidada, de apoio pluripartidário e parte da vida cotidiana institucional.

\section{As práticas de articulação da rede e notificação de casos}

O cotidiano da administração pública demanda muitas ações dos gestores e profissionais. No caso do Iluminar Campinas, nos primeiros 18 meses de funcionamento, as práticas buscavam articular em rede os serviços e capacitar os profissionais envolvidos na atenção às vítimas de violência sexual. Para tanto, buscou-se a capacitação do maior número possível de profisssionais que atuavam nos serviços de diversos setores: profissionais da saúde da rede básica, hospitalar, de urgência e emergência e dos centros de referências; agentes da guarda civil municipal; professores, diretores e orientadores pedagógicos da rede municipal de educação; conselheiros tutelares; conselheiros de direitos; profissionais da rede de assistência social, entre outros. Os objetivos eram sensibilizar os profisisonais para o tema, desenvolver uma atitude empática com as pessoas que sofreram violência, treinar procedimentos-padrão para todos os envolvidos e indicar os passos que deveriam seguir para realizar os encaminhamentos dentro da rede.

No início do Programa, havia muitos desafios práticos e tensões para superar, dentre eles, conse- guir locais adequados para realizar as capacitações, conseguir a liberação dos profissionais do trabalho cotidiano para participar dos encontros e, principalmente, romper a resistência dos profissionais em relação à violência. Geralmente, as pessoas não gostam de lidar com os casos de violência e buscam ignorar sua existência, para não ter que se envolver. Nesse sentido, nos encontros de capacitação, eram utilizadas estratégias de sensibilização, a fim de desenvolver nos participantes a perspectiva de que as vítimas de violência sexual necessitam de acolhimento e cuidado. Assim, ao final das capacitações, a maioria dos profissionais que participavam assumiam publicamente a responsabilidade de cuidar das pessoas que sofreram violência e multiplicavam o aprendizado com os colegas do serviço. Além disso, os encontros possibilitavam também uma articulação pessoal entre os profissionais capacitados oriundos de serviços de diferentes áreas (saúde, educação, segurança pública e judiciário), permitindo que se reconhecessem e pudessem continuar os diálogos e o trabalho em rede no cotidiano das suas funções.

Em um passo importante, retrospectivamente, as reuniões de articulação técnico-políticas com os diferentes setores e instâncias governamentais possibilitaram pactuar as sequências de atividades, os encaminhamentos e as responsabilidades de cada serviço, além de permitir que os problemas de diferentes setores para o atendimento a essas pessoas fossem discutidos e algumas soluções fossem buscadas em conjunto. A partir do momento em que os fluxos estavam desenhados, eram publicados, na página da prefeitura na web, em material impresso e distribuído para as diversas insitutições.

A definição clara dos fluxos, o seu desenho e a sua publicação parecem ter sido um fator fundamental para o sucesso do trabalho em rede. Ou seja, pactuar o que será feito por cada serviço, escrever os fluxos e divulgar essa informação entre todos os atores da rede permite que os profissionais saibam exatamente o que fazer e para onde encaminhar as demandas. Os protocolos escritos e tornados públicos assumiam um papel central no atendimento e são, até hoje, um material que compõe o conjunto de instrumentos desenvolvidos pelo Iluminar. Per- 
mitem também identificar, caso a caso, eventuais falhas nas articulações e encaminhamentos.

As discussões técnico-políticas possibilitaram visualizar as melhores formas de participação de todos os setores e atores da rede, já que, nas reuniões, eram debatidos os limites e as potencialidades dos serviços. Assim, foi pactuado que, uma vez acionada a Guarda Civil Metropolitana (GCM), os agentes que atendessem à vítima ficariam responsáveis por transportá-la a todos os serviços que ela precisasse ir. Ao final do atendimento, esses agentes seriam responsáveis por levar a pessoa até o seu domicílio. Dessa forma, se uma vítima de violência sexual chega sozinha no Centro de Atenção à Saúde da Mulher, após o atendimento, os médicos chamam a GCM, que a transporta para todos os outros serviços da rede para os quais ela tenha sido encaminhada, levando-a até sua casa quando o atendimento for concluído.

O fato de haver transporte entre os serviços para as vítimas é um dos fatores que garantem não só o acolhimento, mas também que elas sigam o fluxo de encaminhamento, já que os serviços são distantes geograficamente, e percorrer essas distâncias em transporte público num momento de fragilidade emocional, física e, em muitos casos, financeira, pode ser muito difícil.

Além disso, à medida que o programa era realizado, as reuniões permitiam alinhar alguns aspectos e aprimorar o atendimento. Por exemplo, foi pactuado com a GCM que, em casos de mulheres e meninas que tenham sofrido violência sexual, uma agente do sexo feminino seria acionada para garantir que elas se sentissem mais à vontade.

Vale lembrar que, apesar da GCM estar sempre pronta para esse atendimento, seguir ou não os encaminhamentos dentro da rede é sempre uma decisão da vítima, se ela for adulta e não se tratar de tentativa de homicídio ou lesão corporal grave.

A inclusão de homens que sofrem violência no contexto prisional ilustra o esforço do Iluminar para atender, na rede de atenção, todas as pessoas em situação de violência. É importante ressaltar que esses casos são notificados como violência sexual e violência institucional.

Outra estratégia que o programa Iluminar adotou para permitir a visualização e o monitoramento dos casos de violência foi a criação do Sistema Municipal de Notificação em Violências (Sisnov). Além de criar o sistema, foi preciso também realizar uma "cultura de notificação", ou seja, convencer os profissionais da importância de notificar e treiná-los para usar o Sisnov. Trata-se de um sistema on-line no qual as diversas instituições que atendem essas vítimas no município podem notificar os crimes. A iniciativa possibilita ampliar a leitura sobre as ações em rede, já que não fica restrita aos serviços de saúde.

A fim de garantir a "cultura de notificação" e o funcionamento contínuo do sistema, desde 2007, o Sisnov, por meio de uma portaria municipal, passou a ser o instrumento oficial de notificação de violência do município de Campinas em todas as áreas de atuação das redes, compondo ainda o Núcleo de Prevenção de Violências e Acidentes. Esse núcleo determina que as ações de notificação sejam incluídas na linha de cuidado às vítimas, investindo no aprimoramento dos fluxogramas de atendimento e apoiando capacitações e atividades de cuidado, além de atuar na prevenção à violência. Assim, hoje, há uma sala de treinamento que conta com 18 computadores, dois instrutores e funciona diariamente no horário comercial, atendendo à demanda dos serviços da rede que agendam treinamentos para seus funcionários por telefone. Esse processo permite que todos os novos atores sejam treinados de modo individualizado e que se forme um vínculo entre os instrutores e os notificadores, o que, por sua vez, facilita o esclarecimento de dúvidas que possam ocorrer no dia a dia do serviço de notificação.

Apesar de todas essas estratégias para facilitar a notificação, os gestores ainda identificam resistência por parte dos profissionais que estão nos serviços para realizar as notificações e buscam estabelecer um processo de acompanhamento contínuo. Assim, quando identificam que um serviço diminuiu o número de notificações, visitam-no e buscam conversar com os responsáveis, para identificar se houve mesmo uma diminuição no número de casos atendidos ou se houve problemas nas notificações.

Em 2008, quando o Ministério da Saúde estabeleceu nacionalmente o Sistema de Informação sobre Agravos de Notificação (Sinan), o Sisnov foi 
adaptado para gerar notificações para o sistema ministerial, mantendo a possibilidade das demais instituições, e não somente a saúde, poderem notificar os casos. A integração dos dois sistemas deu origem ao Sisnov/Sinan, cujos dados permitem que o Comitê de Gestão do Iluminar acompanhe as notificações e monitore as ações da rede. Anualmente, são publicados boletins desse sistema, em versão impressa e digital.

À medida que a rede se articulava e que as ações se consolidavam, algumas atividades foram desenvolvidas, tanto para garantir o bom funcionamento da rede quanto para ampliar o alcance das atividades de cuidado às vítimas de violência sexual. Entre essas ações, destacam-se as do Comitê de Gestão, as de capacitação, a criação das visitas técnicas e o investimento na divulgação do Iluminar nos meios de comunicação.

\section{O Comitê de Gestão}

Composto por representantes das secretarias de Saúde, Assistência Social, Inclusão Social, Segurança Pública e Educação, o Comitê de Gestão conta ainda com representantes das universidades, da sociedade civil e de operadores do direito. As reuniões ocorrem a cada dois meses e têm por objetivo acompanhar as atividades, avaliar os resultados, definir novas metas e resolver conflitos.

Essa gestão compartilhada permite que o pacto entre as instituições seja renovado constantemente e que as ações em rede possam ter continuidade. A partir da avaliação das notificações do Sisnov/Sinan, o comitê identifica as necessidades de ajuste nos fluxos de atendimento, a consistência das fichas, a origem das notificações, os serviços cujo número de notificações aumentou ou diminuiu, os casos sentinela (que apresentam aspectos novos e específicos que não tinham sido previstos e precisam ser acompanhados de perto), entre outras medidas. Após as reuniões, os gestores retornam aos serviços e discutem, com os profissionais envolvidos, a necessidade e a importância de manter as ações pactuadas para a continuidade da rede.

\section{As ações de capacitação continuada}

As ações de capacitação nunca se esgotam, já que há sempre novos funcionários sendo contratados nos serviços envolvidos na rede. Além disso, muitas vezes surgem novas questões no cotidiano do trabalho. Nesse sentido, uma das estratégias desenvolvidas pelo Iluminar foi a discussão de casos nos serviços, um modo de realizar a capacitação permanente nas diversas instituições envolvidas na rede. No caso da GCM, que tem um papel fundamental no programa, já que são seus agentes que realizam o transporte das vítimas aos serviços de saúde, foram incluídos, na grade anual de educação continuada, os conteúdos relativos aos direitos humanos e à violência sexual.

\section{As visitas técnicas}

À medida que ganhou visibilidade, seja pelos prêmios que recebeu ou pelos resultados apresentados, o programa chamou a atenção. Assim, profissionais e gestores de outros municípios envolvidos direta ou indiretamente com a questão do cuidado às vítimas de violência sexual passaram a solicitar visitas para conhecer o modus operandi das ações em rede do Iluminar. Desse modo, foi organizado um programa de visita técnica destinado a gestores do Sistema Único de Saúde (SUS), dos serviços e de profissionais de outras cidades. As visitas ocorrem uma vez por mês, com grupos geralmente de oito pessoas em cada visita. O modelo visa possibilitar que todos possam participar ativamente das atividades, que ocorrem ao longo de oito horas, nas quais o grupo percorre os serviços e conversa com os profissionais da rede. 0 objetivo das visitas é auxiliar os outros municípios na organização e articulação dos serviços de cuidado às vítimas de violência sexual em rede, possibilitando, ao mesmo tempo, que a rede de Campinas troque experiências com profissionais de outras cidades.

\section{A divulgação nos meios de comunicação}

Uma estratégia que tem possibilitado o amplo conhecimento do Iluminar por todo município é a 
divulgação via rádio. Pode-se dizer que ela também é uma ação de educação em saúde, já que busca informar a população campineira sobre a importância de procurar os serviços de saúde o mais rápido possível em casos de violência sexual. Desde 2004, já foram realizadas dez campanhas no rádio, com onze inserções diárias, e o texto é modificado anualmente. Essas campanhas têm possibilitado uma ampla divulgação da noção de que a violência sexual é um problema de saúde pública e que os serviços estão preparados para receber esses casos.

Além das inserções esporádicas na mídia vinculadas a casos ou eventos, há, anualmente, uma entrevista coletiva com os integrantes do programa e os secretários no lançamento do boletim do Sisnov/ Sinan e a discussão dos dados anuais, com grande participação da imprensa local.

\section{Uma breve leitura dos efeitos do Iluminar}

O Iluminar, desde seu início, tem produzido uma multiplicidade de efeitos em diferentes esferas. Ao longo do texto, procuramos demonstrar como os modos de gerir, organizar e articular a ampla rede de profissionais envolvidos no cuidado às vítimas de violência sexual propostos pelo programa têm permitido a continuidade e a consolidação desse programa ao longo do tempo. Um dos efeitos mais significativos do Iluminar foi diminuir os agravos à saúde física e mental sofridos pelas vítimas. Nesse sentido, a preparação dos profissionais envolvidos na rede de atenção para realizar o acolhimento, a escuta e o acompanhamento entre os diferentes serviços da rede (realizado pela GCM) evita que elas tenham que peregrinar entre os serviços num momento em que estão fragilizadas, sendo um grande diferencial qualitativo e um modo de realizar a atenção integral prevista na maioria das políticas de saúde.

A sistematização das notificações dos casos de violência sexual também tem tido muitos efeitos, já que permite o acompanhamento e monitoramento dos casos pelo Comitê Gestor e subsidia as decisões sobre como melhorar o atendimento e realizar ações de prevenção. Um bom exemplo de como a leitura dos dados orienta as ações ocorreu em 2007, quando as notificações no Sisnov/Sinan indicaram que os estacionamentos dos shopping centers da cidade eram os locais de 21 dos 159 casos de estupro atendidos nos meses anteriores. Diante desses dados, o comitê realizou uma capacitação dirigida especificamente aos seguranças dos shopping centers da cidade em abril de 2007.

Ainda no contexto das notificações, os boletins publicados anualmente pelo Sisnov/Sinan possibilitam informar ao público em geral a situação da violência em Campinas e o aumento do número de casos notificados. Para os pesquisadores, o acesso aos dados via TabNet municipal também permite cruzar informações e dados, e assim analisar os resultados dos diferentes programas. A Tabela 1, a seguir, traz uma dessas possíveis análises.

Tabela I - Casos de estupro notificados por ano, Campinas (SP).

\begin{tabular}{lccccccc} 
Ciclo de Vida & 2009 & 2010 & 2011 & 2012 & 2013 & 2014 & Total \\
0-9 Anos & 61 & 57 & 74 & 70 & 64 & 53 & 379 \\
10-19 Anos & 110 & 86 & 117 & 79 & 85 & 85 & 562 \\
20-59 Anos & 103 & 90 & 115 & 92 & 78 & 85 & 563 \\
60 Anos e mais & 4 & 3 & 3 & 0 & 1 & 1 & 12 \\
Total & 278 & 236 & 309 & 241 & 228 & 224 & 1516 \\
\hline
\end{tabular}

Fonte: SISNOV - Coordenadoria de Informação e Informática

Comparando os dados do primeiro ano disponível (2009) com os dados de 2014, embora possamos perceber uma redução, é extremamente preocupante o fato de que, mesmo com inúmeras campanhas, legislações e programas governamentais, Campinas ainda tenha que conviver com mais 
de 200 casos de estupro por ano. Isso mostra que a despeito do município conseguir notificar os casos - o que infelizmente não ocorre em parte importante dos municípios brasileiros -, ainda é fundamental investir em ações de prevenção capazes de diminuir significativamente o número de casos de estupro.

Outro dado disponível mostra que, entre 2009 e 2014, foram realizados 31 abortos legais em mulheres residentes em Campinas (2014). A análise desse número requer pesquisas específicas, porque chama a atenção o baixo número, quando comparado com o número total de estupros ocorridos. Pode-se levantar a hipótese de que a contracepção de emergência realizada no contexto das ações da rede Iluminar para os casos de adolescentes e mulheres em idade reprodutiva esteja obtendo bons resultados, ou a hipótese de que no Brasil o aborto ainda seja uma questão polêmica, impregnada de tabus que podem levar muitas mulheres a manterem gestações indesejadas. 0 objetivo deste artigo não era analisar essas duas hipóteses ou outras possíveis, mas sim mostrar que a simples disponibilização dos dados notificados de casos de violência sexual é capaz de permitir inúmeras pesquisas e estudos sobre o tema.

\section{Considerações finais}

O caso do Iluminar é singular, porque demonstra que a articulação e o funcionamento da rede estão diretamente associados ao envolvimento dos atores e ao constante investimento da gestão do programa na manutenção da conectividade entre os diversos atores. Seja por meio de capacitações, visitas técnicas, reuniões do comitê gestor, pelo acompanhamento de casos sentinela, discutindo e reavaliando as ações, reconhecendo e valorizando a participação das pessoas dos diversos serviços numa rede viva composta por pessoas que estão se empenhando para realizar o cuidado usando todas as potencialidades que o município oferece, a trajetória do Programa Iluminar Campinas mostra que a continuidade - e a sustentabilidade - de uma política pública passa, sem dúvida, pela articulação e o envolvimento de gestores, técnicos e representantes da sociedade civil.

\section{Referências}

BLAY, E. A violência contra a mulher e as políticas públicas. Revista Estudos Avançados, São Paulo, v. 17, n. 49, p. 87-89, 2003.

GUTMANN, A.; THOMPSON, D. Why deliberative democracy. Princeton: Princeton University Press, 2004.

KINGDON, J. W. Agendas, alternatives and public policies. 2. ed. New York: Longman Publishing Group, 1997.

PEDROSA, C. M. O cuidado às pessoas que sofreram violência sexual: desafios à inovação de práticas e a incorporação da categoria gênero no Programa Iluminar Campinas. 2010. Tese (Doutorado em Saúde Pública) - Faculdade de Saúde Pública da Universidade de São Paulo, São Paulo, 2010.

PEDROSA, C. M.; SPINK, M. J. P. A violência contra mulher no cotidiano dos serviços de saúde: desafios para a formação médica. Saúde e Sociedade, São Paulo, v. 20, n. 1, p. 124-135, 2011. Disponível em: <http://dx.doi.org/10.1590/So10412902011000100015>. Acesso em: 10 fev 2016.

SOARES, G. S. Profissionais de saúde frente ao aborto legal no Brasil. Cadernos de Saúde Pública, Rio de Janeiro, v. 19, p. 399-406, 2003. Suplemento 2.

SPINK P. K.; FARAH, M. F. S. Subnational government innovation in a comparative perspective: Brazil. In: SANDFORD, B. (Org.). Innovations in government: research, recognition and replication. 1 ed. Washington, DC: The Brookings Institution, 2008. p. 71-92.

\section{Contribuição dos autores}

Os autores participaram igualmente de todas as etapas de elaboração do artigo.

Recebido: 07/12/2014

Reapresentado: 14/02/2016

Aprovado: 19/02/2016 